\title{
Spectrally Selective Surfaces for Heating and Cooling Applications
}


Downloaded From: https://www.spiedigitallibrary.org/ebooks/ on 26 Apr 2023

Terms of Use: https://www.spiedigitallibrary.org/terms-of-use 


\title{
Spectrally Selective Surfaces for Heating and Cooling Applications
}

\author{
C. G. Granqvist
}

Chalmers University of Technology and University of Gothenburg

Gothenburg, Sweden

Roy F. Potter, Series Editor

Western Washington University

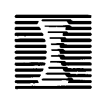

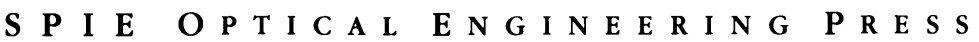

A Publication of SPIE-The International Society for Optical Engineering Bellingham, Washington USA 
Library of Congress Cataloging-in-Publication Data

Granqvist, Claes G.

Spectrally selective surfaces for heating and cooling applications

(Tutorial texts in optical engineering ; v. TT 1)

Includes bibliographical references.

1. Optical coatings. I. Title. II. Series.

TS517.2.G73 $1989 \quad 621.402 \quad 89-10632$

ISBN 0-8194-0228-1

Published by

SPIE-The International Society for Optical Engineering

P.O. Box 10

Bellingham, Washington 98227-0010

Copyright $\odot 1989$ The Society of Photo-Optical Instrumentation Engineers

All rights reserved. No part of this publication may be reproduced or distributed in any form or by any means without written permission of the publisher.

Notes about this publication: The text was input by the author on a Macintosh computer and was reformatted on a Macintosh SE using PageMaker and output on a LaserWriter Plus. The text is printed in 10 point Bookman type.

Composition: Christal Balthazor

Design: Matt Treat \& Kelli McNamara

Printed in the United States of America 


\section{Foreword}

Tutor: to teach or guide, usually individually, in a specific subject

The aim of the Tutorial Texts series is to fulfill the essential role of a tutor for selected topics in optical science and engineering. The Tutorial Texts are based on SPIE short courses. The attendance and the evaluations of those attending the course provide a measure of the degree of interest in the subject matter as well as a qualitative statement about the potential of the course curriculum and lecture notes developing into a book.

Following selection of a candidate course, successful negotiation with the instructor leads to preparation of the Tutorial Text manuscript. The draft manuscript is then submitted for review to one or more independent specialists for critical comment. The manuscript is next revised accordingly and provided in camera-ready format for publication.

This new series has been undertaken with much enthusiasm on the part of the SPIE Optical Engineering Press. We believe that this book, as well as the others to come, reflects the excitement of working with our short course instructors to translate a series of lecture notes into stand-alone texts of a tutorial nature. Indeed, the Tutorial Texts are intended to accomplish, in book format, what the instructor/author does in the course environment. The scope, content, and presentation level are essentially the same in course and book.

This volume by Professor Granqvist is the first Tutorial Text. It emphasizes the fundamental theory, concepts, and considerations of coatings and treatments for controlling surfaces and windows, especially radiative collectors and coolers. It should be a useful resource not only to the optical physicist but also to those in other disciplines, such as architecture, construction, solar energy, aerospace, and physics education, who have an interest in materials for energy efficiency and solar energy utilization.

Roy F. Potter

Western Washington University

29 June 1989 
Downloaded From: https://www.spiedigitallibrary.org/ebooks/ on 26 Apr 2023

Terms of Use: https://www.spiedigitallibrary.org/terms-of-use 


\section{CONTENTS}

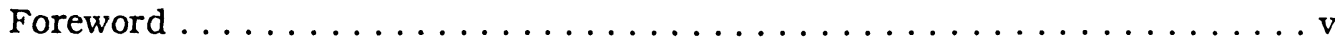

Preface $\ldots \ldots \ldots \ldots \ldots \ldots \ldots \ldots \ldots \ldots \ldots \ldots \ldots \ldots \ldots \ldots$

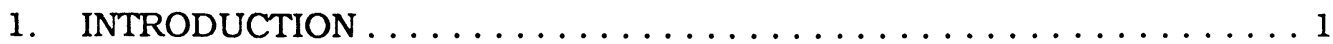

2. NOTES ON THE OPTICAL PROPERTIES OF MATERIALS . . . . . . . . . 5

2.1 Basic thin film optics

2.2 Dielectric functions of homogeneous model materials

2.3 Dielectric functions of nonhomogeneous model materials

2.4 Evaluation of dielectric functions from optical measurements

3. SPECTRAL SELECTIVITY . . . . . . . . . . . . . . . . . . . . 19

3.1 Ambient radiative properties

3.2 Integrated optical properties

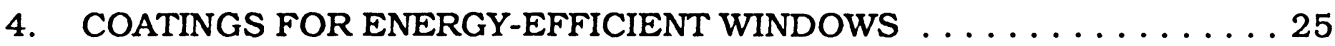

4.1 What is energy efficiency?

4.2 Materials options: A general discussion

4.3 Noble-metal-based coatings

4.4 Doped oxide semiconductor coatings

4.5 Electrochromic coatings

4.6 Thermochromic coatings

4.7 Antireflection treatments

5. SURFACES FOR SELECTIVE ABSORPTION OF SOLAR ENERGY . . . 55

5.1 Desired spectral selectivity

5.2 Review of selectively solar-absorbing surfaces

6. SURFACES FOR RADIATIVE COOLING TO LOW TEMPERATURES . . . 63

6.1 The resource for radiative cooling

6.2 Surfaces with infrared-selective emission

7. APPENDICES .......................... 77

A Selective optical properties of Au films made by ion-assisted evaporation

B Selective optical properties of e-beam evaporated $\operatorname{In}_{2} \mathrm{O}_{3}: \mathrm{Sn}$ films

C Selective absorption of solar energy in coevaporated Co- $\mathrm{Al}_{2} \mathrm{O}_{3}$ composite films

D A primer on large-scale coating technology

8. REFERENCES .......................... 107 


\title{
SPECTRALLY SELECTIVE SURFACES FOR HEATING AND COOLING APPLICATIONS
}

\author{
C. G. Granqvist \\ Physics Department, Chalmers University of Technology, \\ and University of Gothenburg \\ S-412 96 Gothenburg, Sweden
}

\begin{abstract}
PREFACE
This Tutorial Text covers coatings and surface treatments for energyefficient windows of many different kinds, for solar collectors, and for radiative coolers. The desired spectral properties of these surfaces are introduced through a discussion of the radiation that prevails in our natural ambience. The main part of the text is devoted to materials options, coating techniques (mainly evaporation and sputtering), experimental data on optical properties, theoretical models for pertinent materials, and optimization studies with regard to practical applications. The goal is to bridge the gap between fundamental materials science and technological applications and to point out viable options for future research and development. The focus is on basic concepts and ideas rather than physical and mathematical detail. Some background in physics and optics is recommended but not necessary. This Tutorial Text should be of interest to $R \& D$ people in industries, universities, and national and international research institutions who are engaged in issues related to energy efficiency and solar energy utilization.

A large part of the contents of this Tutorial Text is founded on work done at the author's laboratory in close collaboration with a number of students and colleagues. I am particularly indebted to A.M. Andersson, S.M. Babulanam, K.-F. Berggren, T.S. Eriksson, W. Estrada, M.O. Hakim, I. Hamberg, G.L. Harding, A. Hjortsberg, S.-J. Jiang, Z.-C. Jin, K.A. Khan, E.M. Lushiku, G.A. Niklasson, B.E. Sernelius, G.B. Smith, J.R. Stevens, and J.S.E.M. Svensson. I also want to acknowledge the less tangible, but yet pervasively important, inspiration obtained from many years of contact with C.M. Lampert and B.O. Seraphin. Special thanks go to R. Potter of SPIE who suggested that some lecture notes of mine could be used as a basis for a Tutorial Text.
\end{abstract}

Claes G. Granqvist

May 1989 